\title{
Correction to: Efficacy of intravenous plus intrathecal/intracerebral ventricle injection of polymyxin B for post-neurosurgical intracranial infections due to MDR/XDR Acinectobacter baumannii: a retrospective cohort study
}

Sijun Pan ${ }^{1,2+}$, Xiaofang Huang ${ }^{1+}$, Yesong Wang ${ }^{1+}, \mathrm{Li} \mathrm{Li}^{3}$, Changyun Zhao ${ }^{3}$, Zhongxiang Yao ${ }^{2}$, Wei Cui ${ }^{1}$ and Gensheng Zhang ${ }^{1 *}$

Correction to: Antimicrob Resist Infect Control https://doi.org/10.1186/s13756-018-0305-5

The original article [1] contains an error in the Safety analysis sub-section of the results regarding the reported mean creatinine level. The correct mean creatinine level was $42.09 \pm 18.54 \mu \mathrm{mol} / \mathrm{L}$ at 48 hours after polymyxin B injection instead of the reported $41.09 \pm$ $11.46 \mu \mathrm{mol} / \mathrm{L}$.

\section{Author details}

'Department of Critical Care Medicine, Second Affiliated Hospital, Zhejiang University School of Medicine, Hangzhou, Zhejiang 310009, People's Republic of China. ${ }^{2}$ Department of Critical Care Medicine, Anji County People's Hospital, Huzhou 313300, Zhejiang Province, China. ${ }^{3}$ Department of Critical Care Medicine, Zhejiang Hospital, Hangzhou 310013, China.

Received: 2 January 2019 Accepted: 2 January 2019

Published online: 11 January 2019

\section{Reference}

1. Pan S, et al. Efficacy of intravenous plus intrathecal/intracerebral ventricle injection of polymyxin B for post-neurosurgical intracranial infections due to MDR/XDR Acinectobacter baumannii: a retrospective cohort study. Antimicrob Resist Infect Control. 2018;7:8. https://doi.org/10.1186/s13756018-0305-5.

\footnotetext{
* Correspondence: genshengzhang@zju.edu.cn

${ }^{\dagger}$ Sijun Pan, Xiaofang Huang and Yesong Wang contributed equally to this work.

'Department of Critical Care Medicine, Second Affiliated Hospital, Zhejiang University School of Medicine, Hangzhou, Zhejiang 310009, People's Republic of China

Full list of author information is available at the end of the article
}

(c) The Author(s). 2019 Open Access This article is distributed under the terms of the Creative Commons Attribution 4.0 International License (http://creativecommons.org/licenses/by/4.0/), which permits unrestricted use, distribution, and reproduction in any medium, provided you give appropriate credit to the original author(s) and the source, provide a link to the Creative Commons license, and indicate if changes were made. The Creative Commons Public Domain Dedication waiver (http://creativecommons.org/publicdomain/zero/1.0/) applies to the data made available in this article, unless otherwise stated. 